Hospital, who was drowned at the age of twenty. seven in a canoeing accident in Austria in 1937; the bequest came to the Society in 1948 after the death of Lady Stothert.

\section{Agricultural Machinery at the Science Museum}

THE collections of agricultural implements and machinery at the Science Museum, started in 1857, contain a fine historical series from which a selection has been made for public exhibition. They were taken to the country for safety in 1939 and it is only now possible to show them again to the public. The present display occupies the first floor of a building block of which the frame, with temporary wall panels, was constructed before the War as a part of the original East Block, but not completed and furnished until now. In this, the first section of the newly finished museum building to be opened, daylight has been excluded and by use of controlled fluorescent lighting it has been possible to incorporate several novel methods of display. These, while avoiding the transience of the display methods now common in trade exhibitions and the like, have nevertheless been devised with the view of the maximum visual appeal. Recent developments have been shown by means of a series of nearly a hundred models, all to a scale of one inch to a foot, contributed by some twenty firms in the industry. These are displayed against scenic backgrounds with plaster bases and illustrate the work of the up-to-date mechanized farm throughout the seasons of the year. As a centre-piece there is a full-sized sectioned and working combine harvester. Other full-size exhibits include early ploughs, a horse wheel, Bell's reaper of 1826 and the Ivel farm tractor of 1902, the first medium-powered farm tractor driven by an internal combustion engine. In the space at present available it has only been possible to deal with arable farming. The display has been planned in close consultation with the Ministry of Works, which has been responsible for the design and provision of the building, lighting, display cases, etc.

\section{Gas Council Research Centre at Birmingham}

ThE Gas Council has set up a second research centre at the Nechells Gasworks, Birmingham, the work of which will be mainly concerned with the complete gasification of coal. This centre will be administered by the West Midlands Gas Board on behalf of the Gas Council, and its director will be Dr. F. J. Dent, at present assistant director of the Gas Research Board. Dr. Dent has been closely concerned with the experiments upon complete gasification which have been conducted at the Poole Research Station. Great importance is attached to this particular field, and the Gas Council has decided that this work can be accelerated at Birmingham where there are far greater facilities than at Poole, although this does not mean that the work at Poole will cease.

Expedition to Chubb Crater in Northern Canada

The National Geographic Society and the Royal Ontario Museum, Toronto, are sending a joint expedition to far northern Canada to explore the recently discovered Chubb crater. Dr. Victor Ben Meen, a well-known Canadian geologist and director of the Museum, will lead the expedition. The crater site is in northern Quebec between Hudson Bay and Ungava Bay, and the expedition, which is travelling by air, expects to land on a near-by ice-free lake and make camp as near the boulder-strewn crater as is possible. The crater is more than two miles wide and hundreds of feet deep, surrounded by a rim averaging $400 \mathrm{ft}$. high. Dr. Meen saw the crater last year when he surveyed the area in the company of Frederick W. Chubb, a prospector who discovered it, and after whom it is named. Its appearance suggested a tilted cup with one side considerably higher than the other. It is thought that the crater may have been caused by the fall of a meteorite. The expedition is taking modern scientific equipment and will attempt to ascertain the origin of the crater.

\section{Courses and Examinations for Instrument Main-} tenance Mechanics

TeE City and Guilds of London Institute has recently announced the adoption of a new scheme of courses and examinations in instrument maintenance (Subject No. 79). The scheme, which has been drawn up by an advisory committee representing a wide range of interested bodies, is intended for mechanics and technicians concerned in the maintenance, repair and installation of the instruments used for process and production control in industrial plants and in the Armed Services. Particular attention has been given to the requirements of the chemical, iron and steel, and petroleum industries, to fuel economy, and the needs of the Services; but the structure of the scheme is such that it will have wide application. The courses consist of five years of part-time study at a technical college, with an intermediate examination at the end of the third year, and a final examination at the end of the fifth year. There is provision for students holding an appropriate Ordinary National Certificate to enter the course at the beginning of the fourth year. It is hoped that by the provision of these courses the serious shortage of skilled instrument mechanics which is at present handicapping British industry will be effectively reduced. Further details of the scheme, including a pamphlet containing the regulations and syllabuses for the City and Guilds examinations (available shortly, price $6 d$.) can be obtained from the Department of Technology, City and Guilds of London Institute, 31 Brechin Place, London, S.W.7.

\section{A Pioneer in Modern Farm Practice}

A RECENT number of the magazine Scotland (No. 52, June 1951) includes an article extolling the important contributions made by scientific men from Scotland, and in particular from Glasgow, to the development of the industrial revolution and of the atomic age. While these are, for the most part, well known, the author, Prof. Hugh Nicol, of the West of Scotland Agricultural College, also places on record the interesting fact that at the commencement of the nineteenth century a Glasgow citizen, William Harley, author of "The Harleian Dairy System" (1829), ran an internationally famous dairy farm in Glasgow. In the dairy, which held two hundred cows, of which a careful register was kept, there was a steam engine which operated machines for turnipslicing, chaff-cutting and churning. This machine was in operation in 1814 and possibly as early as 1812 , in the same year, as Prof. Nicol puts it, that the famous steamship the Comet first sailed on the Clyde; it is claimed to be the earliest known instance of the use of steam for agricultural purposes.

\section{Representation of Snow in Museum Displays}

THE standards of modern display make great demands on the museum curator, who is constantly 